estudios del habitat $\mid$ FAU

Estudios del Hábitat

ISSN: 2422-6483

aefau@fau.unlp.edu.ar

Universidad Nacional de La Plata

Argentina

\title{
Mar del Plata: el primer boom de la propiedad horizontal, 1948-1960
}

Pegoraro *, Víctor

Mar del Plata: el primer boom de la propiedad horizontal, 1948-1960

Estudios del Hábitat, vol. 18, núm. 1, 2020

Universidad Nacional de La Plata, Argentina

Atribución no comercial compartir igual (CC BY-NC-SA) 4.0 


\section{Mar del Plata: el primer boom de la propiedad horizontal, 1948-1960 \\ Mar del Plata: the first "construction boom" of horizontal property biuldings, 1948-1960}

Victor Pegoraro *

Universidad Nacional de Mar del Plata, Universidad de

San Andrés, CEHis, CONICET, Argentina

pegorarovictorn@gmail.com

Recepción: 30 Junio 2019

Aprobación: 06 Abril 2020

Publicación: 30 Junio 2020

Recepción: 30 Junio 2019

Aprobación: 06 Abril 2020

Publicación: 30 Junio 2020

\section{ReSUMEN:}

Los estudios sobre vivienda e historia urbana en la Argentina sostienen que a mediados del siglo XX se registró un "boom de la construcción" de edificios en propiedad horizontal. Ello se habría desatado recién tras la caída del peronismo y, sobre todo, en la década siguiente (o sea, no durante el gobierno de su impulsor). Este diagnóstico privilegia a Buenos Aires, por encima de otras localidades, desestimando el peso inmediato de la ley de1948 en la nueva inversión inmobiliaria. El caso de Mar del Plata permite relativizar la hipótesis puesto que aun antes de su sanción ya se evidenció una significativa actividad. En el presente artículo intentaremos dilucidar este fenómeno y las estrategias impulsadas por los agentes inmobiliarios porteños que promocionaron la edificación con fines turísticos en el balneario de moda. Estos actores instalarían sus oficinas temporariamente en la costa entablando relaciones con constructores y contratistas locales, protagonistas del ciclo.

Palabras clave: Mar del Plata, Propiedad horizontal, Construction boom, Boom de la construcción.

\section{Abstract:}

Studies related to housing and urban history in Argentina show that in the mid-twentieth century there was a "construction boom" of horizontal property biuldings. This situation could have occurred only after the fall of Peronism and, especially, in the following decade (i.e. not during the government of its promoter). This diagnosis privileges Buenos Aires above other locations, dismissing the immediate effect of the law (1948) in the new real estate investment. The case of Mar del Plata allows us to relativize the hypothesis, since a significant activity was already evident even before its enactment. Our intention in this article is to elucidate this phenomenon and the strategies driven by the real estate agents in Buenos Aires that promoted building for tourism purposes in the trendy seaside resort. These agents would set up temporary offices in the coast, developing relationships with local builders and contractors, the key players of the cycle.

KEYWORDS: Mar del Plata, Horizontal property buildings, Construction boom .

\section{INTRODUCCIÓN:}

La ley 13.512 denominada de "propiedad horizontal" fue sancionada durante el primer gobierno de Juan Domingo Perón en septiembre del año 1948 y reglamentada por Decreto Nacional 18.734 en agosto del año siguiente. ${ }^{2}$ La misma facilitaría la densificación del núcleo urbano, el acceso a la propiedad de viviendas (antiguamente de alquiler) y la proyección de la actividad contractual privada. ${ }^{3}$ No se trataba de un tipo particular de construcción sino de una figura jurídica que se incorporaba al Código Civil, como ya lo habían hecho otros países, de forma de economizar costos de transacción y de administración. El sistema creado para adquirir una casa-habitación, al hacer posible la adquisición por unidades independientes de valor más reducido, fue creando un incentivo poderoso para la construcción de edificios de departamentos ya que permitió la integración de su costo total con el aporte de varios interesados. De este modo, se regulaba la división y organización de un inmueble en un plano horizontal mediante un Reglamento de Copropiedad (Ley 13512/48).3 
En realidad, vino a reglamentar y a legislar una situación ya presente, y en tensión, relacionada al problema de la vivienda en la Argentina (Germani, 1955; Aboy, 2008). De esta manera, en las próximas décadas garantizaría el acceso a la propiedad a nuevos sectores sociales de acuerdo a los diferentes niveles en que se sistematizó la norma, por ejemplo, en propiedades de una sola planta o en barrios alejados. Empero, paulatinamente en los principales cascos céntricos del país se materializó una inusitada especulación de tierras que modificó el plano catastral original y conllevó la concreción de operaciones inmobiliarias de envergadura que modificaron el entorno socio-espacial.

El impacto en la ejecución de obras y en la inversión inmobiliaria marcó un parteaguas en la historia urbana de la Argentina. Por todo ello, el tópico ha sido tratado relevantemente por la historiografía específica, junto a importantes estudios urbanos realizados por arquitectos y sociólogos. Estos especialistas han trabajado temáticas relacionadas con las políticas públicas en torno a la vivienda, la edificación privada, la producción estilística y material, la historia de la vida cotidiana, el consumo, el mercado inmobiliario, la estética, la cultura de habitar, etc. (Yujnovsky, 1984; Torres, 2006; Liernur y Ballent, 2014; Contreras, 2005).

En general, dichos trabajos se circunscriben a la ciudad de Buenos Aires manifestando los cambios acaecidos en el parque habitacional y en el mercado urbano de la principal urbe del país. Las posibilidades que brindaba la norma generó la entrada de nuevos agentes y la consolidación de las empresas tradicionales de la actividad, quienes lograron aprovechar un alto rendimiento económico en la producción del espacio urbano (Torres, 2006:17). El correlato de este fenómeno fue la concentración de un nuevo tipo de edificación en altura en las zonas céntricas y en diferentes barrios como Recoleta, Barrio Norte, Palermo, Belgrano y Caballito (Aboy, 2010:4).

Siguiendo esta línea, pese al cambio de legislación las diversas disposiciones adoptadas por el peronismo en los años siguientes impidieron que este impacto fuera inmediato. En este sentido, el "boom de la construcción" se registraría recién tras el alejamiento de esta fuerza política, o sea, no durante el gobierno de su impulsor, y sobre todo en la década de 1960 y los primeros años de la de 1970 (Ballent, 2014a: 490). En esa especie de transición del primer lustro de la década de 1950 primó la reconversión de edificios viejos (antiguamente de renta), más que la nueva edificación, por lo que "no parece haber tenido como efecto práctico un aumento de la inversión por parte del capital privado” (Aboy, 2007:90).

Esta idea está presente en la mayoría de los trabajos, compartida como premisa general del desarrollo urbano argentino. Sin embargo, el registro empírico sólo privilegia el caso porteño y la incidencia que tuvo dicha reglamentación en ese espacio. Trascendiendo estas barreras, una historia de la propiedad horizontal en Argentina debería prestar atención a otros contextos y a la movilidad de los mismos actores en el interior del país.

El caso de Mar del Plata permite relativizar aquella hipótesis ya que desde 1949 se inaugurarían nuevos edificios bajo dicho sistema a lo largo del litoral, manifestando un importante dinamismo de las inversiones privadas. La nueva norma potenció un "boom de construcción” en altura antes que en cualquier lugar del país. En contraste, ello representa un caso excepcional dado el impacto inmediato del nuevo régimen de construcción en un mercado urbano con claras ventajas comparativas (precio del $\mathrm{m} 2$, menores restricciones reglamentarias, acceso a lotes) para el desarrollo de nuevas transacciones

La evidencia empírica muestra que la construcción venía siendo una de las principales actividades económicas locales dado por la gran demanda que representaba el alojamiento de los turistas y veraneantes. De hecho, históricamente, la oferta habitacional había seguido este derrotero ya desde finales del siglo XIX (Pegoraro, 2017b). Así, la década de 1950 acució cambios inmediatos en materia edilicia registrándose un "boom" que superaría en retrospectiva el volumen de edificación de los años sesenta, comúnmente vistos como el periodo paradigmático de masificación y consumismo por la bibliografía general citada.

Ello se dio en el contexto más amplio de grandes cambios para el escenario local: a mediados de siglo, la ciudad balnearia era considerada como la "meca nacional del turismo" y se estaba afianzando como un destino masivo y popular, dando paso a un verdadero "fenómeno de masas" que alcanzaría su apoteosis en los 
años sesenta (Torre y Pastoriza, 2019). En este sentido, confluyeron dos procesos mutuamente influyentes, aunque con lógicas diversas, que consolidaron la atracción estival: por un lado, un efusivo boom inmobiliario con destino a la clase media argentina y, por otro, una apertura a nuevas capas sociales del disfrute de playas.

En el presente artículo intentamos probar estas afirmaciones y dilucidar las estrategias impulsadas por las firmas, junto a reconocidos agentes inmobiliarios de Buenos Aires, que promocionaron desde temprano la edificación frente al mar y con fines turísticos en el balneario de moda. Al parecer no dejarían de invertir, sino que lo harían en otro lado (fuera de Buenos Aires) donde la reproducción del capital podía llegar a ser más grande y segura. Dichos actores instalarían sus oficinas temporariamente en la costa entablando relaciones con las empresas constructoras y contratistas locales, que se convertirían en protagonistas del ciclo económico. Mar del Plata sería el receptor más importante, empero el fenómeno también se extendería a los balnearios vecinos como Necochea o Miramar, aunque en menor grado.

Por último, las publicidades de edificios que circulaban por diferentes soportes a lo largo y ancho del país resultan referencias de primer orden para indagar sobre la oferta, las estrategias de venta y las características de los departamentos ofrecidos. Estas imágenes fueron muy fuertes en la época ya que atrajeron a múltiples compradores fuera de Mar del Plata (sobretodo, porteños), animando a los asiduos (y nuevos) visitantes a adquirir y consumir este tipo de productos.

\section{La ley de Propiedad horizontal: Mar del Plata y el país}

La puesta en práctica de la ley de propiedad horizontal (1948) desató una euforia constructiva con diferentes ritmos en las principales ciudades del país. En este sentido, el resultado más evidente se materializó en el aumento desmesurado de la construcción de edificios de departamentos en altura durante los "años del desarrollismo" hasta por lo menos el "Rodrigazo" (1975), caracterizado por una demanda del consumo propio de las clases medias (Sebreli, 2011). Por otra parte, también vale destacar que la política del Banco Hipotecario Nacional fue de suma importancia para la consecución de planes de vivienda económica donde intervendrían diversos sindicatos, cooperativas, mutuales, entes oficiales y otras entidades intermedias en la construcción de complejos habitacionales (Ballent, 2014b; Gargantini, 2003).

Volviendo al punto central, verbigracia, en Rosario, ciudad ligada al comercio exportador, se desataría también un auge de la construcción privada seguido de un "boom inmobiliario" en la década de 1960 en el área central, orientada a sectores de ingresos altos y medios (Lanciotti, Lavih, Brizuela y Kofman, 2017). Por contraste, en Capital Federal el proceso siguió similares derivaciones pero, claro está, con otro ritmo dado el tamaño del mercado y la frontera económica. En este caso, el despegue de nuevas obras de forma masiva le siguió a un periodo de estancamiento (1950-1957), donde primó más fuertemente un proceso de subdivisión de departamentos ya construidos bajo la modalidad de renta (Aboy, 2007:239).

No obstante aquel desarrollo, el patrón de crecimiento y la naturaleza urbana de Mar del Plata hicieron que este fenómeno se desarrollara de modo muy diferente y con otra velocidad al resto de las localidades argentinas. ${ }^{4}$ La condición de ciudad turística impuso una lógica diferente en el mercado de trabajo, las transacciones inmobiliarias, el rol de los actores, la función de los objetos construidos, la movilidad de inversores y en la valorización del suelo. Ello obedecía a su lugar geográfico privilegiado en la costa atlántica, su cercanía con respecto a la capital del país y la funcionalidad urbana que había imperado por décadas (Pegoraro, 2018).

En comparación, el impacto del nuevo régimen de construcción fue inmediato mientras que en otras importantes aglomeraciones urbanas sería más tardío. Como referencia se ha tomado la caída del peronismo, pero, como afirma Aboy (2010:2), el análisis de la vivienda y las formas de vida trascienden una mera cronología basada estrictamente en los cambios políticos. De hecho, el caso local manifiesta una constante edilicia de larga duración más allá de la influencia o no de las políticas económicas circunstanciales emanadas de diferentes gobiernos nacionales o provinciales. 
Como premisa general, afirmamos que aquí la tendencia general marcada por los índices de la construcción representó un caso atípico. Al comparar las cifras registradas por las estadísticas oficiales con otras localidades, durante el periodo estudiado la relación resultante (coeficiente) entre el número de habitantes estables y la cantidad de obras ejecutadas resulta sugestivo (cuadro $\mathrm{N}^{\circ} 1$ ). Mientras que importantes centros como Rosario y La Plata se mantienen en un promedio de $1 \mathrm{~m} 2 /$ hab.; en Capital Federal el coeficiente es muy bajo dada su densidad de población; Mar del Plata cuadriplica las cifras por el destino de las construcciones y la demanda externa de departamentos.

CUADRO NO 1

CANTIDAD DE M2 CONSTRUIDOS POR HABITANTE EN DISTINTAS CIUDADES DEL PAÍS
\begin{tabular}{|c|c|c|c|c|}
\hline Año/ciudad & Mar del Plata & Rosario & Capital Federal & La Plata \\
\hline 1948 & $3,3 \mathrm{~m}^{2}$ & $0,79 \mathrm{~m}^{2}$ & $0,3 \mathrm{~m}^{2}$ & $0,82 \mathrm{~m}^{2}$ \\
\hline 1952 & $4 \mathrm{~m}^{2}$ & $1,04 \mathrm{~m}^{2}$ & $0,5 \mathrm{~m}^{2}$ & $0,96 \mathrm{~m}^{2}$ \\
\hline 1955 & $3,55 \mathrm{~m}^{2}$ & $0,95 \mathrm{~m}^{2}$ & $0,39 \mathrm{~m} 2$ & $1,35 \mathrm{~m}^{2}$ \\
\hline 1957 & $4,05 \mathrm{~m}^{2}$ & $\mathrm{~s} / \mathrm{d}$ & $0,37 \mathrm{~m}^{2}$ & $\mathrm{~s} / \mathrm{d}$ \\
\hline
\end{tabular}

REVISTA CONSTRUCCIONES, CÁMARA ARGENTINA DE LA CONSTRUCCIÓN, 1948-1960

La cantidad de turistas arribados expresan un crecimiento exponencial: desde los 504.517 de la temporada 1945-1946, se contabilizaría el triple para fines de los años cincuenta (Pastoriza, 2011). En este sentido, podemos entrever una simbiosis significativa, pero cierta dependencia, entre la construcción privada, el turismo y un "mercado inmobiliario del ocio" que fue el más importante del país. No sólo ello, existieron periodos que no se condijeron con el comportamiento general del sector a nivel nacional en cuanto a la permanencia de un nivel sostenido de actividad.

Cabe destacar que, en vísperas de la promulgación de la mencionada norma ya se construían edificios, pero bajo el régimen de "condominio" (propiedad colectiva) donde los departamentos no eran adjudicados por venta por la empresa constructora, como sucedería posteriormente. En cambio, se creaba una sociedad o asociación por núcleo de adquirentes asignando los departamentos a sus diferentes miembros, pero reteniendo los derechos de propiedad en cabeza de un único propietario (que en ese caso era la propia sociedad). ${ }^{5}$

$\mathrm{Al}$ igual que en otras ciudades, en un primer tiempo, varios edificios construidos con función de renta fueron inaugurados, otros convertidos y muchos vendidos bajo el nuevo sistema ya que resultaba más redituable al disponer de unidades independientes, ya sea de una o más plantas, pudiendo contrarrestar el congelamiento del precio de los alquileres establecidos por política oficial. En este plano, los derechos individuales de propiedad estaban "más claros" al poder ejercerse de forma exclusiva el uso privado, la hipoteca, renta o venta del inmueble (Coloma, 2001).

Los nuevos horizontales fueron poblando las zonas más versátiles en un mercado urbano elástico donde todavía el verticalismo de las edificaciones no era una pauta en una ciudad poblada de chalets. Pese a la existencia de varios conjuntos de renta y hoteles con altura de ocho a diez pisos, los edificios marcaron rápidamente una trasformación del perfil urbano y de la postal marplatense. Este proceso generaría la valoración del suelo en ciertas zonas aledañas, claro está, a la costa, al Casino, al Hotel Provincial, a "la Bristol” (la playa más popular), a la Terminal de Ómnibus y a Playa Grande (sector más predilecto). Estas fueron las zonas más dinámicas de transacciones comerciales y las que constituyeron la referencia señalada en la publicidad para los vendedores/ compradores a lo largo y ancho del país. ${ }^{6}$

En el cuadro $\mathrm{N}^{\circ} 2$ observamos una estadística en torno a los permisos otorgados por la Municipalidad en materia de edificación. Aunque, vale decir, este tipo de datos utilizados en diferentes investigaciones, si bien son un buen instrumento de análisis, poseen algunas limitaciones ya que: a) no todo expediente presentado se vuelve "obra"; b) no se solicita certificado final en todos los casos; c) no discrimina en tipos de construcción; 
d) no representa el nivel efectivo de actividad actualizado ya que la obra siempre se realiza tiempo después y no coincide con el año del "permiso"; e) los datos consignados pueden no registrar la totalidad de los metros cuadrados construidos en la ciudad; $\mathrm{f}$ ) existen numerosas obras en contravención terminadas sin permiso alguno, que no se contemplan en la estadística; g) en algunos casos la aprobación de expedientes demora muchos años si es una "excepción” al código o al reglamento de edificación.

CUADRO NO 2

ESTADÍSTICA COMPARATIVA DE LA CONSTRUCCIÓN PRIVADA (1947-1960)

\begin{tabular}{|c|c|c|c|c|c|}
\hline Año & $\begin{array}{c}\text { Permisos otorgados } \\
\text { (nuevas y } \\
\text { refacciones) }\end{array}$ & $\begin{array}{c}\text { Superficie } \\
\left(\mathbf{m}^{2}\right)\end{array}$ & $\begin{array}{c}\text { Importe } \\
\text { calculado por } \\
\mathbf{m}^{2} \mathbf{( \$ )}\end{array}$ & $\begin{array}{c}\text { Costo de la } \\
\text { Importe total } \\
\text { aproximado }\end{array}$ & $\begin{array}{c}\text { construcción } \\
\text { en pcia. de Bs. } \\
\text { As. }\end{array}$ \\
\hline $\mathbf{1 9 4 7}$ & 2401 & $244.947,43$ & $\mathrm{~s} / \mathrm{d}$ & $\mathrm{s} / \mathrm{d}$ & $\mathrm{s} / \mathrm{d}$ \\
\hline $\mathbf{1 9 4 8}$ & 2538 & $276.402,65$ & $\mathrm{~s} / \mathrm{d}$ & $\mathrm{s} / \mathrm{d}$ & $\mathrm{s} / \mathrm{d}$ \\
\hline $\mathbf{1 9 4 9}$ & 2544 & $362.006,09$ & $\mathrm{~s} / \mathrm{d}$ & $\mathrm{s} / \mathrm{d}$ & 100 \\
\hline $\mathbf{1 9 5 0}$ & 3252 & $366.307,40$ & 700 & $210.772 .555,00$ & 126 \\
\hline $\mathbf{1 9 5 1}$ & 3549 & $421.730,44$ & 850 & $358.470 .871,50$ & 152 \\
\hline $\mathbf{1 9 5 2}$ & 4207 & $473.038,78$ & 831,14 & $455.180 .867,00$ & 208 \\
\hline $\mathbf{1 9 5 3}$ & 3812 & $285.015,74$ & 982,12 & 271.934 .658 & 213 \\
\hline $\mathbf{1 9 5 4}$ & 3314 & $289.712,16$ & 1032,45 & 295.491 .332 & 230 \\
\hline $\mathbf{1 9 5 5}$ & 3258 & $368.470,99$ & 1132 & 417.738 .659 & 241 \\
\hline $\mathbf{1 9 5 6}$ & 2911 & $415.748,61$ & 1320,26 & 553.389 .638 & 335 \\
\hline $\mathbf{1 9 5 7}$ & 2871 & $422.369,73$ & $\mathrm{~s} / \mathrm{d}$ & 699.255 .733 & 367 \\
\hline $\mathbf{1 9 5 8}$ & 2051 & $327.597,95$ & $\mathrm{~s} / \mathrm{d}$ & 617.772 .604 & 530 \\
\hline $\mathbf{1 9 5 9}$ & 1518 & $172.997,50$ & $\mathrm{~s} / \mathrm{d}$ & 471.033 .780 & 963 \\
\hline $\mathbf{1 9 6 0}$ & 1647 & $179.786,35$ & $\mathrm{~s} / \mathrm{d}$ & 668.775 .513 & 1077 \\
\hline
\end{tabular}

DIRECCIÓN DE OBRAS PRIVADAS (MUNICIPALIDAD DE GRAL. PUEYRREDÓN)

Por lo expresado, la serie señala sólo tendencias generales y comportamientos (registrados) de la actividad, por lo que indudablemente debe ser complementado con otro tipo de documentación cuantitativa y cualitativa. Para la primera cuestión, incorporamos otro insumo más fiable (aunque, también tiene ciertos problemas) que nos permite reconstruir el fenómeno durante la década de los cincuenta, como son los expedientes de construcción privada. Para ello hemos realizado un riguroso relevamiento de campo (calle por calle y barrio por barrio) a lo largo y ancho de la ciudad donde se ha censado cada edificio en propiedad horizontal construido. Posteriormente, hemos consultado individualmente los permisos municipales de edificación de cada uno trayendo como correlato un vasto universo de estudio.

A continuación, presentamos la cantidad anual de edificios inaugurados en el periodo estipulado. Cabe destacar, que los tiempos de construcción dependen de varios factores (clima, productividad, organización, financiamiento, etc.), sean aleatorios, ponderables o imprevisibles, por lo que ello también puede alterar dicha estadística. Entonces, la heterogeneidad en la cantidad de unidades anuales responde a diferentes razones: algunas minúsculas (por ejemplo, las inauguraciones se daban en diciembre o en enero indistintamente, modificando las cifras); sustanciales, cambios de expectativas o incertidumbre económica. ${ }^{7}$ Lo cierto, que los edificios se entregaban, preferiblemente, antes del comienzo de la temporada y demandaban entre 12 y 24 meses de concreción, que era lo usual en la época.

Como se puede observar, los picos se advierten más o menos a principios y finales de la década, seguidos de una depresión o contracción que devuelve la dinámica con altos y bajos. Esta información complementa la estadística sobre superficies edificadas que no suele discriminar la "vivienda unifamiliar" (individual) de la "multifamiliar" (colectiva), permitiendo captar este tipo de construcción. 
CUADRO NO 3

CANTIDAD DE EDIFICIOS NUEVOS CONSTRUIDOS EN MAR DEL PLATA (1948-1960)

\begin{tabular}{|c|c|c|}
\hline Año & $\begin{array}{c}\text { Cantidad de edificios } \\
\text { construidos }\end{array}$ & $\begin{array}{c}\text { Promedio anual de plantas } \\
\text { (altura) }\end{array}$ \\
\hline 1950 & 19 & 7 \\
\hline 1951 & 25 & 7 \\
\hline 1952 & 50 & 8 \\
\hline 1953 & 36 & 9,5 \\
\hline 1954 & 10 & 8 \\
\hline 1955 & 20 & 9,5 \\
\hline 1956 & 46 & 9,6 \\
\hline 1957 & 80 & 10 \\
\hline 1958 & 67 & 10 \\
\hline 1959 & 60 & 9,6 \\
\hline 1960 & 61 & 10,8 \\
\hline
\end{tabular}

\begin{abstract}
Elaboración propia en base a expedientes de construcción (Archivo de Obras Privadas-Municipalidad de Gral. Pueyrredón); Estadísticas del Centro de Constructores y Anexos; publicidades y avisos clasificados Diario La Capital/ Diario La Nación/ Diario La Prensa/El atlántico (1948-1960); archivos de empresas; entrevistas orales; revistas especializadas, entre otras.
\end{abstract}

El cuadro $\mathrm{N}^{\circ} 3$ muestra, a diferencia de uno de "superficie construida" o a construir $(\mathrm{m} 2)$, la realidad efectiva (no futura ni posible) del fenómeno, por lo que resulta "más certero" a la hora de analizar las variaciones temporales. A la vez, se centra en un tipo particular de construcción como son los "edificios" (a partir de tres plantas) haciendo viable su discriminación y manipulación. Sin embargo, no hay que perder de vista que el resultado material proviene de una acción llevada a cabo por los actores (inversores, inmobiliarias, empresas constructoras, subcontratistas y trabajadores) con anterioridad al momento de presentar el expediente de obra (permisos, planos, certificados, firmas profesionales). Generalmente, ello sucedía dos o tres años (incluso más) con anterioridad a la inauguración de la obra. Por ende, el nivel de actividad manifiesta también el horizonte de expectativas que tenían los protagonistas en ese instante al empezar el trámite y encargar la construcción.

El análisis de ambas series, permite vislumbrar que en Mar del Plata se registró un "boom de construcción" en propiedad horizontal ya a inicios de la década de 1950 y que pervivió durante todo el decenio con un muy buen nivel de actividad. No obstante, se vislumbran dos periodos de mayor movimiento: 1949-1953 y 1956-1960; y otro de cierta retracción, 1954-1955. Cabe destacar, que recién en el bienio 1969-1970 se reconocerían cifras más elevadas en lo que concierne a $\mathrm{m} 2$ construidos cuando los años anteriores se habían mantenido estables. ${ }^{8}$ Ya en 1978 podemos evidenciar la mayor cantidad de edificios desde que se puso en práctica la norma.

Todo ello nos hace reflexionar acerca de la afirmación de que la década de 1960 fue la más dinámica en cuanto a construcciones y a operaciones inmobiliarias a nivel país. El análisis del fenómeno se debe matizar dada la expresión de una actividad por demás muy fluctuante y atada a los vaivenes económicos. A la vez, el análisis de otros contextos fuera de Buenos Aires nos permite dimensionar mejor un proceso histórico no unitario ni coherente en sí mismo. Pese a la continuidad de ciertas variables macroeconómicas que entrarían en crisis con el "Rodrigazo", la puesta en vigor de la ley de propiedad horizontal distó de ser lineal y homogénea. Así, lo manifiesta el caso de Mar del Plata lo que permite rever algunas consideraciones generales sobre el periodo.

\title{
LAS OPERACIONES INMOBILIARIAS Y EL USO DE LA PUBLICIDAD EN LOS AÑOS CINCUENTA
}

Históricamente, la costa atlántica vislumbró un rol singular en el abanico de destinos turísticos nacionales permaneciendo en el horizonte de posibilidades de los argentinos. En este sentido, el veraneo en Mar del Plata 
había permeado en la sociedad desde la predilección de las clases altas, los grandes apellidos y presidentes en la "Belle Epoque"; más tarde, en la cultura de masas y, sobre todo, en el consumidor medio y metropolitano de la ciudad de Buenos Aires. Principalmente, a él se dirigían los estímulos sensoriales de la publicidad a mediados del siglo XX (mar, aire fresco, naturaleza, calor), el gusto, la moda y aquellos valores asociados al ocio (descanso, tiempo libre, vacaciones, relax) que liberarían de los dramas propios de las grandes urbes. ${ }^{9}$

Múltiples sectores sociales se sintieron interpelados por la promoción del balneario, vale el ejemplo de la llegada de los obreros a partir del peronismo. No obstante, la posibilidad de tener una propiedad frente al mar como segunda residencia para fines de descanso y veraneo a partir de la década de 1950 fue un rasgo económico y cultural estrictamente constitutivo de las clases medias destinado a perdurar. Los edificios de departamentos como bienes de consumo modelaron aspiraciones de época que sólo podría alcanzar una franja social que estuviera en condiciones materiales de hacerlo. Prontamente, se transformaron en objetos deseados y necesarios para mantener y ostentar un determinado estilo de vida.10

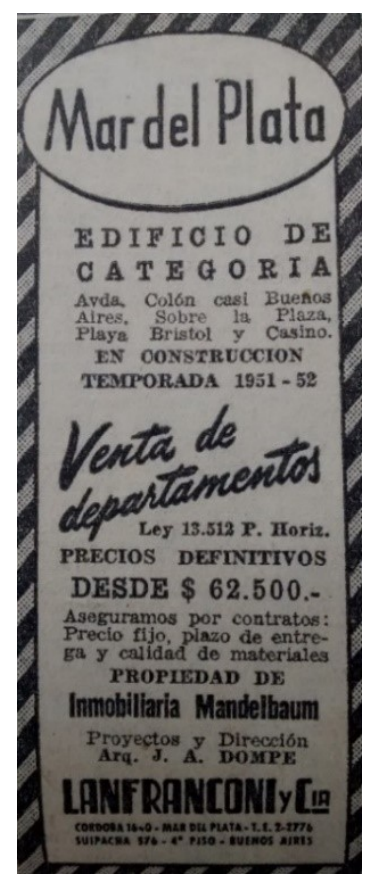

FIGURA 1A

PUBLICIDADES DE EDIFICIOS EN VENTA EN LA PRENSA DE BUENOS AIRES

LA NACIÓN, 30/12/1950 


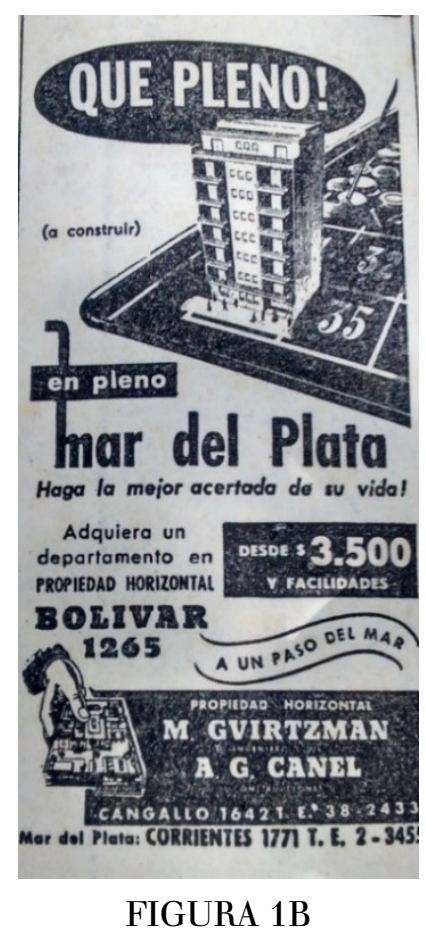

PUBLICIDADES DE EDIFICIOS EN VENTA EN LA PRENSA DE BUENOS AIRES

LA NACIÓN, 01/12/1951

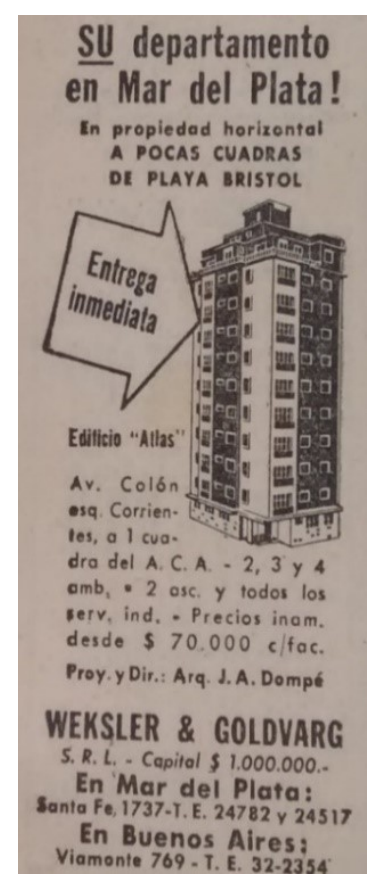

FIGURA 1C

LA NACIÓN, 03/12/1952

Los avisos correspondían a inmobiliarias e inversionistas reconocidos en el ámbito porteño donde se remarcaba el veraneo, el descanso y el ocio en el ambiente formado por la playa, el casino y el sol. El lenguaje utilizado y las comodidades ofrecidas apuntaban a un público lector que podía conocer ciertas referencias comunes a asiduos visitantes o a quienes escuchaban hablar de "la Bristol", "el Hotel Provincial", "el Casino Central”, "la Plaza Colón”, entre otras. La tenencia de una propiedad fija en Mar del Plata superaba la oferta 
de alojamiento tradicional basada en la hotelería en sus diversas modalidades u otras formas de alquiler como casas particulares o departamentos de renta. ${ }^{11}$

Las posibilidades de ofrecer esta serie de coordenadas geográficas para fines turísticos trajeron como correlato la valorización del suelo y una demanda espontánea de venta de terrenos o propiedades en sus proximidades. Así, los inversionistas foráneos y locales se lanzaban a conseguir las zonas más codiciadas para los negocios inmobiliarios donde la retribución sería más segura e inmediata ya desde la realización del pozo de obra. Como consecuencia, múltiples estructuras (chalets, villas veraniegas, viviendas bajas, comercios, hoteles pequeños, casas de renta, etc.) cayeron bajo la piqueta demoledora de la primera hora.

\section{LOS INVERSORES PORTEÑOS: ACTIVADORES DEL SISTEMA}

Los inversores e inmobiliarias que ya tenían gran radio de acción en Buenos Aires fueron los primeros en ver la oportunidad de hacer negocios en Mar del Plata bajo el régimen de la propiedad horizontal. Algunos venían desempeñándose en la ciudad con sucursales de las casas matrices e intermediarios entre dueños, martilleros y otros profesionales. El resto de las firmas contaban con una estructura prexistente que permitió su instalación en la ciudad convirtiéndose en "horizontalistas".

El contrato profesional para la materialización de los proyectos fue variopinto. En principio, las inmobiliarias podían contratar a terceros (porteños o marplatenses) para el diseño del edificio y ellas se encargaban de la venta de las unidades. ${ }^{12}$ En segundo lugar, ciertas empresas edificadoras, estudios de arquitectos e ingenieros reconocidos en Capital Federal llevaron adelante numerosas realizaciones durante la década de $1950 .{ }^{13}$ Todo el conjunto señalado contrataría para los trabajos a empresas constructoras familiares (en su mayoría, de proveniencia italiana), que ya venían desarrollándose desde décadas atrás.

Estos actores externos al medio local fueron los que insertaron las formas novedosas de comercialización y los primeros promotores. La venta se realizaba en pesos "en cuotas" a "precios fijos e inamovibles" y, en ocasiones, "al costo" con un interés del 6 o 7\%. Por ejemplo, la firma Berner y Berner S.A. Inmobiliaria, constructora y Financiera (adquirente de Bernardo Berner, Villafañe y Berner) fue una de las originales empresas desarrolladoras de la propiedad horizontal en Capital Federal y Mar del Plata. En esta última, sus edificios fueron paradigmáticos ofreciendo el siguiente plan en cuotas trimestrales y semestrales para un edificio del centro: $20 \%$ al firmar el boleto de compra-venta; $50 \%$ en cuotas mensuales del $5 \%$ cada una hasta el momento de la posesión; $30 \%$ en hipoteca a 1 año de plazo con el $8 \%$ de interés. Estos actores externos al medio local fueron los que insertaron las formas novedosas de comercialización y los primeros promotores. La venta se realizaba en pesos "en cuotas" a "precios fijos e inamovibles" y, en ocasiones, "al costo" con un interés del 6 o 7\%. Por ejemplo, la firma Berner y Berner S.A. Inmobiliaria, constructora y Financiera (adquirente de Bernardo Berner, Villafañe y Berner) fue una de las originales empresas desarrolladoras de la propiedad horizontal en Capital Federal y Mar del Plata. En esta última, sus edificios fueron paradigmáticos ofreciendo el siguiente plan en cuotas trimestrales y semestrales para un edificio del centro: $20 \%$ al firmar el boleto de compra-venta; $50 \%$ en cuotas mensuales del 5\% cada una hasta el momento de la posesión; 30\% en hipoteca a 1 año de plazo con el $8 \%$ de interés. ${ }^{14}$ En ocasiones, existía un $5 \%$ de descuento por pago al contado y la financiación de un 25\% por un préstamo del Banco Hipotecario. 


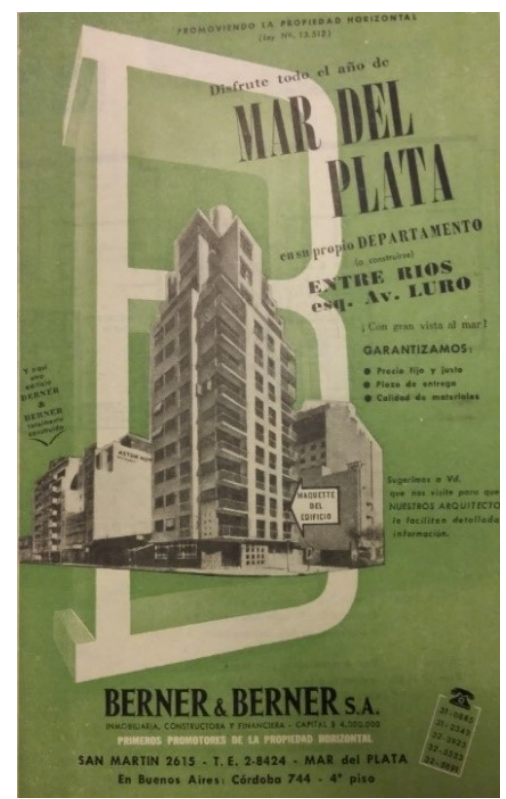

FIGURA 2A

FOLLETOS PUBLICITARIOS DE EDIFICIOS, DÉCADA DE 1950 ARCHIVO PRIVADO DE EMPRESAS CONSTRUCTORAS LOCALES.

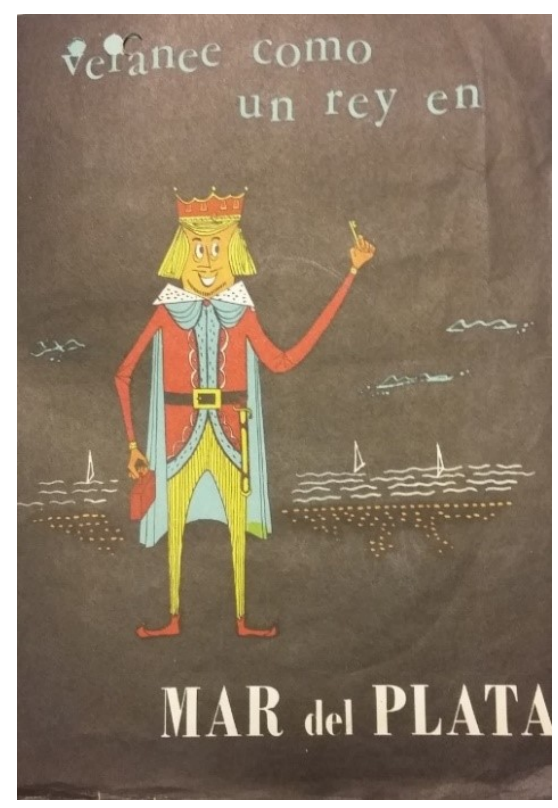

FIGURA 2B

FOLLETOS PUBLICITARIOS DE EDIFICIOS, DÉCADA DE 1950 ARCHIVO PRIVADO DE EMPRESAS CONSTRUCTORAS LOCALES 


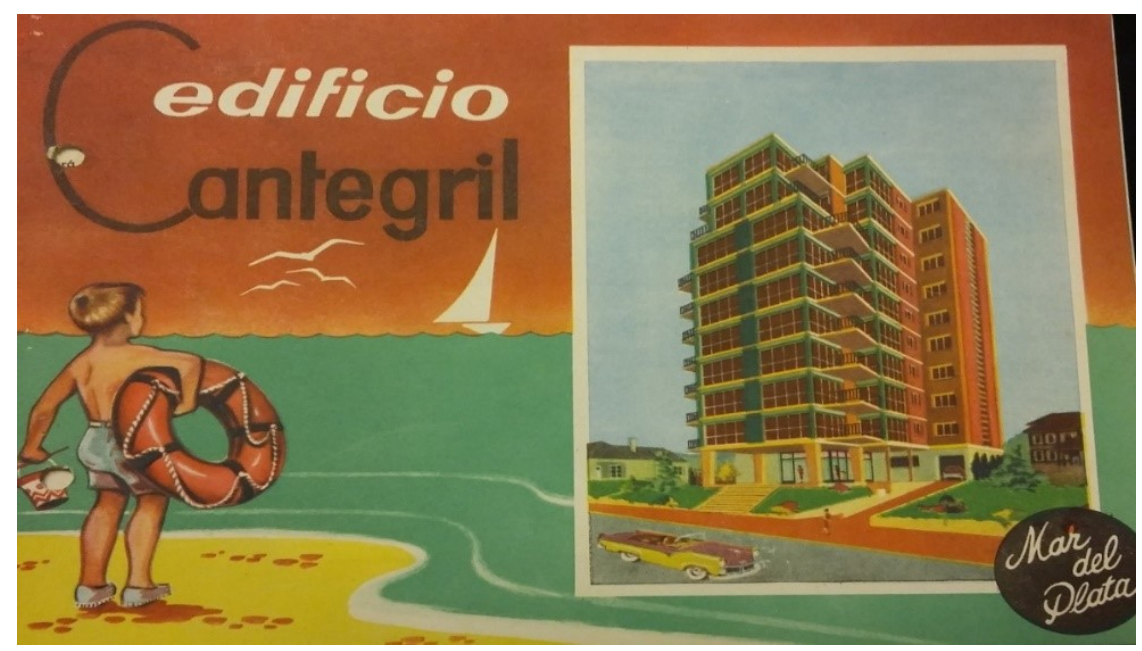

FIGURA 2C

FOLLETOS PUBLICITARIOS DE EDIFICIOS, DÉCADA DE 1950 ARCHIVO PRIVADO DE EMPRESAS CONSTRUCTORAS LOCALES.

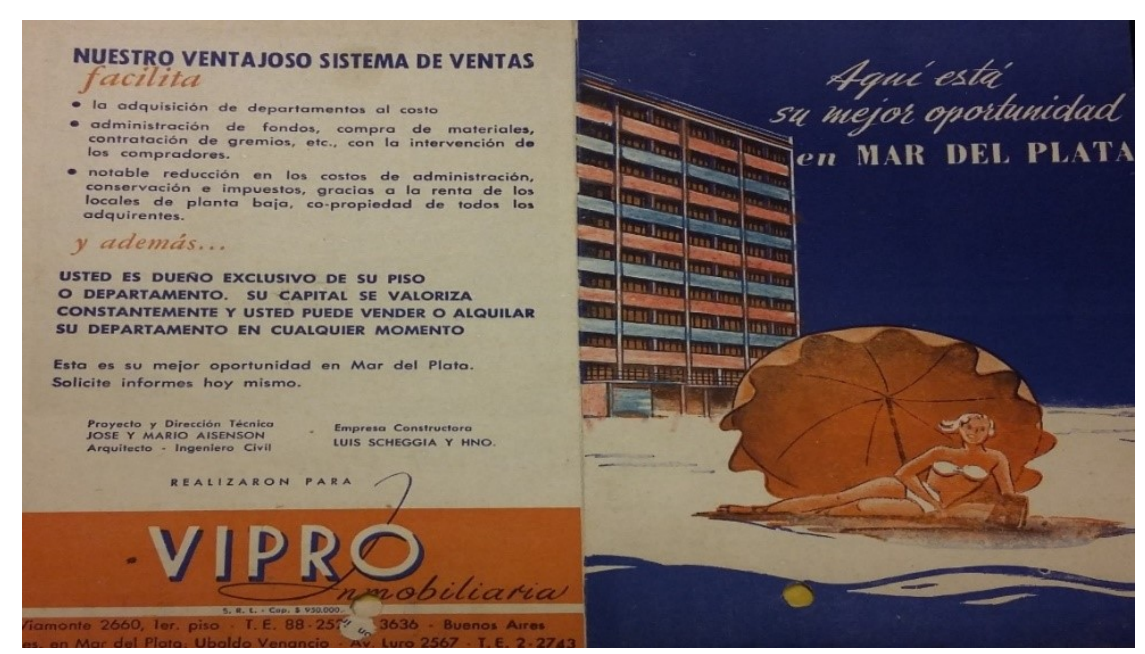

FIGURA 2D

FOLLETOS PUBLICITARIOS DE EDIFICIOS, DÉCADA DE 1950 ARCHIVO PRIVADO DE EMPRESAS CONSTRUCTORAS LOCALES

Berner y Berner SA poseía un capital de $\$ 5.000 .000$ y promovía la construcción junto con la venta de departamentos, desde la misma sanción de la ley 13.512, que ellos consideraban como una "obra patriótica", afirmando ser "los primeros promotores". ${ }^{15}$ Desde 1948 anunciaban en diarios nacionales y locales su acción desplegada, aun antes de estar reglamentada la ley. Mientras que un año después finalizaron su primer edificio en el balneario, al cual le seguirían otros en los años posteriores construidos por empresas familiares locales. ${ }^{16}$

Frente a los planes de financiación de estas empresas, la actividad tuvo varios alicientes dados por la facilidad de préstamos otorgados por el Banco Nación, el Banco Provincia y, esencialmente, el Banco Hipotecario. Por ejemplo, en 1958 un informe parlamentario del diputado Isaac Breyter (UCRI) sobre la actuación del Banco Hipotecario Nacional llegaba a la conclusión de que los créditos otorgados por tal entidad, y que estaban destinados a resolver el problema de la "vivienda permanente", en Mar del Plata habían sido utilizados casi exclusivamente para levantar residencias y habitaciones de veraneo y renta contrariando así su misión social. ${ }^{17}$ Pese al contexto político de proscripción del peronismo y de crítica a su gestión, el testimonio da cuenta de un fenómeno por demás interesante. 
No obstante, la conducta no fue lineal de acuerdo a los vaivenes de la política económica, financiera y crediticia mediados por gobiernos democráticos y de facto. De hecho, la principal forma de financiación provenía del mismo circuito a través de la venta de pozo de obra y la comercialización de documentos como moneda de cambio entre los gremios interactuantes (Pegoraro, 2018).

\section{LA CONSTRUCCIÓN LOCAL: LAS EMPRESAS FAMILIARES Y LAS INVERSIONES}

A esa altura Mar del Plata ya contaba una importante industria de la construcción formada por un nutrido grupo de contratistas y subcontratistas locales que habían experimentado una movilidad social ascendente (Bartolucci, 2009).

Indudablemente, pese a la capacidad capitalista de los nuevos inversionistas, y el impulso dado en los primeros años, serían las firmas constructoras locales las que protagonizarían el ciclo en estas décadas centrales del siglo XX. En general, se trataba de pequeñas y medianas empresas basadas en una organización familiar y cuasi artesanal. De este modo, el titular había sido el propio fundador ejerciendo la propiedad y la dirección, creando estructuras de negocios para transformar estas oportunidades del momento en nuevas actividades con éxito.

El conjunto de empresas familiares estaba conformado por una veintena de apellidos ligados a la actividad desde las décadas previas. Estas generaciones de padres e hijos transformaron sus emprendimientos en empresas de gran peso dedicados exclusivamente a levantar edificios en altura. Paralelamente, al amparo del circuito económico fueron desarrollándose los demás rubros (gremios anexos) y el sector de compra/ venta de propiedades. En este sentido, harían su entrada agentes inmobiliarios locales y externos que incidieron fuertemente en el ámbito privado. ${ }^{18}$

a promulgación de la ley de propiedad horizontal en 1948 cambiaría la órbita y proyección de la mayoría de estas empresas locales al ampliar inusitadamente el radio y volumen de acción de manera versátil. Desde temprano se acoplaron al negocio levantando edificios multifamiliares por encargo y propios en asociación con otros gremios. Estas sociedades circunstanciales entre gremios (constructores y anexos) fueron corrientes, resultando muy eficaces y eficientes a la hora de emprender obras de magnitud donde cada uno aportaba su experiencia, parte del capital y mano de obra al proyecto global. De esta manera, se minimizaban los riesgos, se lograban mesurar los costos y se aceleraban los ritmos de construcción.

Dos de las firmas paradigmáticas de este proceso fueron:

-SEMAR SRL (Sociedad de Empresas Marplatenses de la Propiedad Horizontal): desde 1949 conformó una cadena completa de trabajo entre profesionales y gremios de obra (construcción, proyecto y dirección, yesería, obras sanitarias, electricidad y gas, pintura, carpintería), es decir, que estaban representados como eslabones las diferentes ramas de actividad (contratistas y subcontratistas), lo que permitía una vinculación natural y eficaz desde la confección del proyecto hasta las terminaciones interiores. Cada uno desarrollaba su especialidad y cobraba por el trabajo realizado (sea en dinero o en cantidad de $\mathrm{m} 2$ ), ulteriormente distribuían la retribución por la venta de los departamentos o ellos mismos se quedaban con algunos. El capital inicial fue aportado por varios de los "socios inversionistas" (locales y porteños) y hasta 1960 desarrollaron diez edificios de número correlativo.

-GAMEC SRL (Gremios Asociados Marplatenses Empresa Constructora): una de las firmas más importantes que llevó a cabo algunos horizontales propios mediante asociaciones de hecho entre diversos integrantes de la albañilería y otros rubros como la yesería y casas de materiales para la construcción. Las etapas y las labores de cada gremio eran coordinadas por la empresa contratista y los edificios se entregaban antes del verano ya que habitualmente los compradores eran externos al medio. La comodidad de los ambientes era variada, aunque se pensaba en unidades de temporada para ser utilizadas dos o tres meses. 


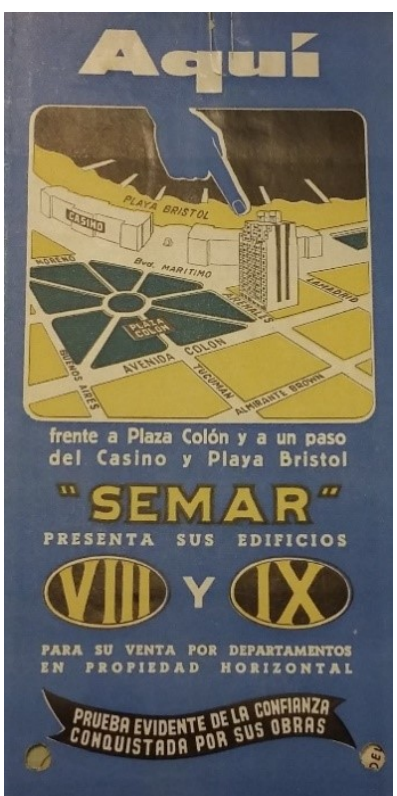

FIGURA 3A

PUBLICIDADES DE EDIFICIOS FOLLETO SEMAR, AÑO 1956

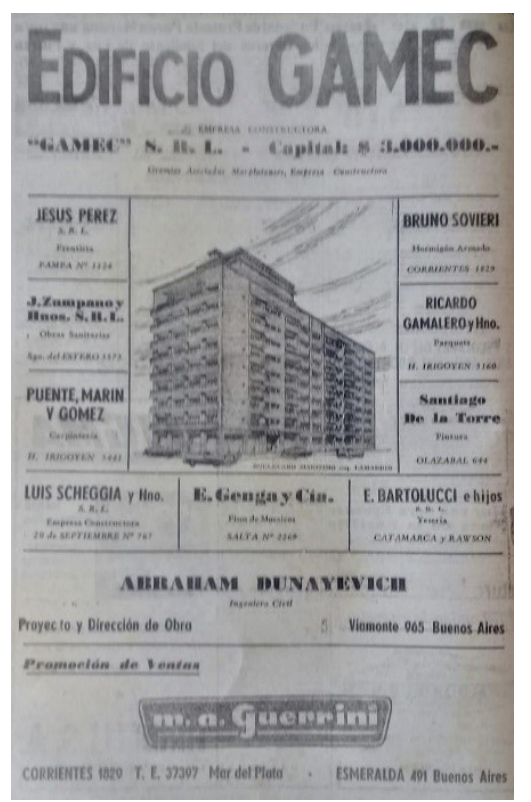

FIGURA 3B

PUBLICIDADES DE EDIFICIOS DIARIO EL ATLÁNTICO, AÑO 1957

Los empresarios familiares ya actuaban como agentes inmobiliarios antes de la moda de la propiedad horizontal. Por años habían invertido con capital propio en tierras, chalets y casas de renta. Ahora, la estructura de estas sociedades permitía la relación directa con el cliente mediante la instalación de una oficina en Buenos Aires y un puesto de ventas en la misma obra. La inversión fue fuerte al contar con liquidez y con unidades de departamentos propios para ser vendidos rápidamente. Ello permitía alimentar el circuito económico comenzando nuevas obras en diferentes zonas del centro, pagando a otros gremios y/o equipando el mobiliario de los nuevos inmuebles. Todo ello no hacía más que ensanchar la estructura ocupacional del área y posicionarse en el mercado como potentes sociedades capitalistas. Se trataba de una apuesta grande ya 
que era un negocio disímil al de trabajar para un tercero o un financista foráneo en el cual se percibía sólo un honorario.

Por su parte, la estrategia de integrar varias sociedades al mismo tiempo era paralela al desarrollo de la actividad dentro de cada familia empresaria. Gracias a este desarrollo durante toda la década de 1950, en la siguiente, sobre todo el grupo de los "constructores" y los "yeseros", desarrollaron sus propias marcas en un mercado donde sus apellidos ya eran conocidos por los consumidores gracias a las vinculaciones que habían tejido durante años.

Por ejemplo, un edificio requería un 30\% de capital propio y dejaba alrededor de un $70 \%$ de utilidades, mientras que la venta se hacía en cuotas mensuales (y en pesos) al igual que las promociones y planes lanzados por las firmas de Buenos Aires. Las cuotas posteriores a la posesión servían para financiar la próxima obra que ya se encontraba en construcción al mismo tiempo en otro lote de la ciudad. La reproducción de la rueda productiva era en cadena, automática y continua donde el ritmo de trabajo no disminuía.

Frente a los inversores porteños y las empresas familiares, en tercer lugar, resulta necesario destacar también la participación de profesionales abocados a la realización de los proyectos como ingenieros y arquitectos. Éstos podían ser vernáculos o foráneos, pero la mayoría logró insertarse e integrarse en el gran abanico de posibilidades que el mercado ofrecía. Algunos crearon sus propios emprendimientos y otros supieron trabajar para las firmas de Buenos Aires más importantes generando un circuito de trabajo muy flexible. Por último, los diferentes sindicatos de la construcción tuvieron un peso decisivo al logar reunir a la gran masa de obreros y bregar por mejoras salariales. La actividad daba trabajo durante todo el año, antes y después de la temporada, por lo que ofrecía un polo de atracción para la radicación de trabajadores de la zona en búsqueda de empleo.

\section{Reflexiones FinALES}

En nuestro país las diferentes investigaciones provenientes del campo de la historia, así como también de la historia de la arquitectura argentina, sostienen que el boom de la construcción de edificios bajo el régimen de propiedad horizontal se registró tras la caída del peronismo (o sea, no durante el gobierno de su impulsor) y, sobre todo, en la década siguiente. Este diagnóstico privilegia el caso de Buenos Aires, por encima de otras localidades, desestimando el peso inmediato de la puesta en práctica de la ley del año 1948 en la nueva inversión inmobiliaria (más allá de la reconversión de edificios viejos).

El caso de Mar del Plata demuestra que la actividad de la construcción se potenció inmediatamente con las nuevas oportunidades que ofrecía el sistema. La ciudad fue quizás el primer destino de importantes capitales asentados en la capital del país que pudieron reproducirse de forma ampliada hacia la construcción para turismo. Ello la diferencia del concierto de localidades argentinas donde el primer efecto fue tímido y, en gran medida, posterior como indican las investigaciones sobre el tópico.

Las consecuencias de la famosa ley pueden ser ya vislumbradas de manera resonante durante la década de 1950, y, aun, antes de la caída del peronismo. El "boom de construcción” en propiedad horizontal permite advertir aquí dos periodos de gran movimiento: 1949-1953 y 1956-1960; y otro de cierta retracción, 1954-1955.

Cabría preguntarnos ¿Por qué Mar del Plata fue la excepción a nivel país? Parece ser que el litoral marítimo presentaba mejores oportunidades que otros mercados urbanos del país. Ello explicaría la fuerte inversión inicial bajo el sistema de propiedad horizontal en un mercado de tierras muy elástico, con menores restricciones, bajo precio del $\mathrm{m} 2$ (con respecto a ciertas zonas de Buenos Aires), venta fácil y la posibilidad de reproducción ampliada del capital inmobiliario, dado que la legislación oficial reprimía el agio estipulando que no se podía ganar más de un $20 \%$ en el negocio de la propiedad de altura. Por otra parte, el balneario se había convertido en moda, en un destino masivo y en centro de consumo. El valor simbólico de la posesión de una segunda propiedad frente al mar fue muy fuerte para las clases medias. Los inmuebles fueron también una reserva de ahorro para este segmento de la población. 
Por último, las imágenes aparecidas en diarios, revistas y folletos publicitarios de edificios encendieron la demanda del público externo a Mar del Plata garantizando la factibilidad de las acciones emprendidas por los actores directamente involucrados. Las referencias señaladas de la propaganda giraban en torno al ocio, al veraneo y al descanso, pero también a lugares ineludibles para todo turista: el Casino, la Bristol, la Plaza Colón, la Rambla y Playa Grande.

En síntesis, en el periodo analizado existió una diversidad de agentes involucrados en la venta, construcción y proyección del sistema de la propiedad horizontal. La plaza inmobiliaria marplatense atrajo no sólo a grandes inversores, capitales y consumidores (compradores) porteños con novedosas formas de comercialización sino también rosarinos y de otros lugares del país. No obstante, la prevalencia de los actores locales a la hora de construir y vender fue muy fuerte. Estas empresas familiares supieron sacar rédito de sus lazos con el medio local, el conocimiento del oficio, las relaciones con profesionales e inversionistas foráneos. De formar parte de sociedades de hecho se convertirían en SRL, SCA o SA en el decenio de 1960 aprovechando las continuidades en torno a las provechosas condiciones del mercado inmobiliario.

\section{Bibliografía}

Aboy, R. (2008). Arquitecturas de la vida doméstica. Familia y vivienda en Buenos Aires, 1914- 1960. Anuario IEHS $23,2008,355-384$

Aboy, R. (2010). Ciudad, espacio doméstico y prácticas de habitar en Buenos Aires en la década de 1950. Una mirada de los departamentos para las clases medias. Buenos Aires: Mundo Nuevo, Nuevos Mundos

Arboy, R. (2007) Vivir con Otros. Una historia de los edificios de departamentos en Buenos Aires, 1920-1960 (Tesis de Doctorado en Historia inédita), Universidad de San Andrés, Buenos Aires

Ballent, A. (2014a) Casa Colectiva, monobloque, propiedad horizontal. Desplazamientos y Cruces de modelos en la habitación colectiva. En: Liernur, J. y Ballent, A. La casa y la multitud. Vivienda, politica y cultura en la Argentina moderna. Buenos Aires: Fondo de Cultura Económica

Bartolucci, M. (2009). Pequeños Grandes Señores Italianos y estrategias de ascenso, Mar del Plata 1910-1930. Buenos Aires: Editorial Prometeo

Coloma, G. (2001). Breve análisis económico dela propiedad horizontal. Universidad del Centro de Estudios Macroeconómicos de Argentina, Working Papers Series

Contreras, L. (2005) Rascacielos porteños. Historia de la edificación de altura en Buenos Aires (1580-2005). Buenos Aires: Gobierno de la Ciudad de Buenos Aires

Gargantini, D. (2003). Breve revisión histórica de la política habitacional argentina. Documento de Trabajo, Serie Arquitectura, Editorial de la Universidad Católica de Córdoba

Germani, G. (1955). Estructura social de la Argentina. Buenos Aires: Raigal

Lanciotti, N., et. alt. (2017). Notas sobre el mercado inmobiliario en Rosario, 1916-1966. Ponencia presentada en las X Jornadas de Economía Crítica, Buenos Aires, 7, 8 y 9 de septiembre

Liernur, J. y Ballent, A. (2014). La casa y la multitud. Vivienda, politica y cultura en la Argentina moderna. Buenos Aires: Fondo de Cultura Económica

Nielsen, M. y Rodríguez, L. (2016). Del turismo de elites al turismo de masas. Historia, turismo y patrimonio: el caso de Necochea (1900-1976) (Tesis de Licenciatura en Turismo), Universidad Nacional del Centro de la Provincia de Buenos Aires, Tandil

Pastoriza, E. (2011). La conquista de las vacaciones. Breve historia del turismo en la Argentina. Buenos Aires: Edhasa

Pegoraro, V. (2018). Apuntes para una historia de la propiedad horizontal en Mar del Plata (1948-1982). Pasado Abierto, Vol. IV, $\mathrm{N}^{\circ} 7,166-187$

Pegoraro, V. (2017a). De gremio a corporación. Empresarios familiares, militantes gremiales y agentes sociales: el CCyA de Mar del Plata (1935-1977) (Tesis de Maestría en Historia), Universidad Nacional de Mar del Plata, Mar del Plata 
Pegoraro. V. (2017b). Mar del Plata, el "mercado inmobiliario del ocio". La industria de la construcción entre 1930 y 1981. Anuario del CEED, 9, 9, 213-253

Sebreli, J. (2011). Buenos Aires: vida cotidiana y alienación. Buenos Aires: Sudamericana

Torres, H. (2006) El Mapa Social de Buenos Aires (1940-1990). Serie Difusión № 3. Buenos Aires: Ediciones FADU Yujnovsky, O. (1984). Claves Politicas del Problema Habitacional Argentino, 1955-1981. Buenos Aires, GEL

\section{Notas}

* Profesor, Licenciado y Magíster en Historia (Universidad Nacional de Mar del Plata). Doctorando en la Universidad de San Andrés y becario doctoral del Consejo Nacional de Investigaciones Científicas y Técnicas (CONICET).

2 En su artículo $\mathrm{N}^{\circ} 1$ establecía que: "Los distintos pisos de un edificio o distintos departamentos de un mismo piso o departamentos de un edificio de una sola planta, que sean independientes y que tengan salida a la vía pública directamente o por un pasaje común podrán pertenecer a propietarios distintos, de acuerdo a las disposiciones de esta ley. Cada piso o departamento puede pertenecer en condominio a más de una persona”.

3 Se amalgamaban dos derechos: el de dominio sobre cada piso o departamento y de condominio en varias partes indivisas del edificio (escaleras, hall de entrada, terrazas, jardines, galenas, pórticos, puerta de entrada, ascensores, portería, servicios, incineradores de residuos, etc.). Revista Construcciones, Cámara Argentina de la Construcción. № 70, marzo, 1951

4 Desde 1937, las endebles estadísticas municipales mostraban ya el inicio de lo que hemos denominado un "boom horizontal" (1930-1950) dada la expansión edilicia.

5 Deducciones en torno a expedientes de construcción de edificios de renta de la década de 1940. Archivo de Obras Privadas, Municipalidad de Gral. Pueyrredón

6 El análisis de numerosas listas de compradores de departamentos, a través de las fuentes propias de las empresas constructoras, manifiestan que la mayor parte de los mismos provenían de Capital Federal y el Gran Buenos Aires, siguiéndole algunas provincias de Cuyo o del Norte del país.

7 De hecho, la relación entre la actividad de la construcción y los ciclos de "stop and go" resulta estrecha.

8 En 1969 se registraría un total de 811.842 m2 y en 1970, 794.870 m2. Anuario Estadístico, año 1974, Municipalidad de Gral. Pueyrredón

9 En este plano, las publicidades y folletos de venta que circulaban por inmobiliarias, diarios de Buenos Aires (La Nación, Clarín, La Prensa, La Razón), revistas (Mundo Argentino, La Revista de Mar del Plata) y otros medios de difusión de todo el país produjeron poderosas imágenes que resultaron ser exitosas al provocar la compra inusitada y eufórica de una franja social que demandaba estos bienes. Además, las revistas más leídas generaban imágenes sobre "la ciudad feliz" (Caras y Caretas, Tía Vicenta, Rico Tipo, Panorama, Siete Días, Mafalda, Patoruzú), generando un amplio repertorio de placeres para los lectores.

10 De hecho, existen numerosos casos en los que los compradores manifestaban que en su lugar de origen alquilaban la vivienda donde residían. Fuente: Lista de compradores (Archivo de empresas constructoras de Mar del Plata) y entrevistas orales

11 Ello traería una crisis de la hotelería tradicional, entre 1957 y 1962 desaparecieron un total de 42 hoteles, sea por demolición o por ser convertidos en propiedad horizontal. Diario La capital, 8/02/1962

12 Mandelbaum, Berner y Berner SA., Weksler y Goldvarg SRL, Borensztjn, Gicovate y Cía. SRL, Vilas y Etchegoyen, Gvirztman y Canel, FACILP SRL, SyBA SRL, Bengen Hnos., Inmobiliaria Mathov, Dolmen Inmobiliaria, Safaro Inmobiliaria, Livingston SRL, Alford SRL, Vipro Inmobiliaria, AADESA (Administración Argentina de Edificación SA), Pustelnik. Fuente: diarios La Nación, La Prensa, La Capital (1948-1960)

13 Aisenson, Guillermo A. Peña, Dunayevich, Raichberg y Cía. SRL, Edificadora Levinton, Viñals y Aspesi, Solari y Lorderbaum SRL, A. Ringach y Cía., Dezeta S.A, Diez Hermanos, Inmobiliaria Maral, Marbec, Cazzaniga y Cía. Fuente: Publicidades en diarios La Nación, La Capital (1948-1960)

14 Publicidad Berner y Berner SA, Año 1950. Archivo Arq. Raúl Camusso (colección privada), Centro Documental CAPBA IX, Colegio de Arquitectos de la Pcia. de Buenos Aires Distrito IX, Mar del Plata

15 Diario La Capital, 26/11/1949

16 Diario La Capital, 24/12/1951

17 Diario La Prensa, 16/09/1958

18 Las inmobiliarias paradigmáticas del periodo harían su aparición recién en los sesentas controlando el mercado: NanniniBarrera, Coste y Freuler, Álvarez e Iñurrieta, Fraga y Cía. SCA, Di Tullio, etc. 
Estudios DEL HÁBitAT, 2020, 18(1), JUNio, ISSN: 2422-6483

CC BY-NC-SA 